\title{
Comparison of Osteoimmunological and Microbiological Parameters of Extra Short and Longer Implants Loaded in the Posterior Mandible: A Split Mouth Randomized Clinical Study
}

\section{Usporedba osteoimunoloških i mikrobioloških parametara ekstremno kratkih i dužih implantata u stražnjim dijelovima donje čeljusti pod opterećenjem: randomizirano kliničko istraživanje »split-mouth»}

\footnotetext{
${ }^{1}$ Bilge Karcı, Alanya Alaaddin Keykubat University, Faculty of Dentistry, Department of Periodontology, Alanya, Antalya, Turkey Zavod za parodontologiju Fakulteta dentalne medicine Sveučilišta Alanya Alaaddin Keykubat, Alanya, Antalija, Turska

2 Elif Oncu, Necmettin Erbakan University, Faculty of Dentistry, Department of Periodontology, Konya, Turkey

Zavod za parodontologiju Fakulteta dentalne medicine Sveučilišta Necmettin Erbakan, Konya, Turska
}

\begin{abstract}
Objectives: This study aimed to evaluate the levels of TNF- $\alpha$, PGE, RANKL, RANK, OPG, the markers of periimplant bone loss in peri-implant crevicular fluid obtained around standard and extra short implants. Moreover, the levels of putative oral pathogens were investigated in the submucosal biofilm samples. Material and Methods: The implants were divided into two groups according to their lengths: standard $(\geq 8 \mathrm{~mm})$ and extra short $(4 \mathrm{~mm})$. A total of 60 implants were researched in 30 patients. The probing depth (PD), clinical attachment level (CAL), presence of bleeding on probing (BOP), 3-year survival rate (CSR), and bone loss (BL) were measured. Results: No statistically significant difference was found in the values of PD, CAL, BOP, CSR, and BL between the groups $(P>0.05)$. Total amounts of PGE ${ }_{2}$, TNF- $\alpha$, RANKL, RANK, OPG, and RANKL/OPG were not statistically significantly different between the groups $(P>0.05)$. The abundance of $F$. nucleatum, $T$. forsythia, $P$. intermedia, $P$. gingivalis, $S$. oralis and $T$. denticola was compared between the groups and the results were not statistically significant $(P>0.05)$. Conclusion: The results of this study suggested that PGE, TNF- $\alpha$, RANKL, RANK, OPG, and RANKL/OPG in PICF, as well as microbiological parameters in submucosal biofilms, were similar between standard $(\geq 8 \mathrm{~mm})$ and extra short $(4 \mathrm{~mm})$ implants. Therefore, the implant length does not seem to influence the bone loss, levels of osteoimmunological and microbiological markers in the peri-implant tissues and survival rates.
\end{abstract}

Received: April 14, 2021

Accepted: July 15, 2021

Address for correspondence Bilge Karcl

Alanya Alaaddin Keykubat University Faculty of Dentistry Department of Periodontology Alanya, Antalya, Turkey Phone: +902425106140 Fax: +902425106144 bilge0013@hotmail.com

MeSH terms: Dental Implantation; Osseointegration; Bone-Implant Interface; Biofilms Author keywords: Dental Implants; Immunology; Microbiology

\section{Introduction}

Dental implants are usually considered an alternative treatment option in edentulous patients. Following tooth extraction, the vertical and horizontal areas in the alveolar socket are significantly reduced (1). Clinicians have to consider more complex and time-consuming techniques for reconstruction of the maxilla and mandible, such as a sinus lift or vertical guided bone regeneration procedures $(2,3)$; however, these procedures must be precise and are often accompanied by high costs, high morbidity, and intra- and postsurgical complications. Short dental implants have been suggested as a less invasive, cheaper, and faster alternative to prevent the disadvantages of surgical techniques and for the rehabilitation of toothless areas $(4,5,6,7)$. A large number of randomized controlled clinical trials demonstrated that the long-
Uvod

Dentalni implantati obično se smatraju alternativnim terapijskim rješenjem za bezube pacijente. Nakon ekstrakcije zuba znatno se smanjuju vertikalne i horizontalne dimenzije alveole (1). Kliničari moraju razmatrati kompleksnije i vremenski zahtjevnije rekonstrukcijske tehnike gornje i donje čeljusti, kao što su odizanje dna sinusa ili vertikalno vođena regeneracija kosti $(2,3)$. No, ti postupci moraju biti precizni, a često su i skupi te praćeni visokim morbiditetom i komplikacijama tijekom kirurškoga zahvata i poslije njega. Kao jeftinije, manje invazivno i brže zamjensko rješenje pojavili su se kratki implantati kojima se sprječavaju nedostatci kirurških tehnika, a mogu nositi žvačne jedinice u bezubim područjima $(4-7)$. U velikom broju randomiziranih kontroliranih kliničkih istraživanja autori su istaknuli uspješnost i dugotraj- 
term success and survival rates of short implants were similar to those of standard long implants (8-10).

Accumulation of microbial dental plaque around the implant is the most important cause of implant loss (11). If the microbial attachment is not removed, diseases such as periimplant mucositis and peri-implantitis may occur and result in implant loss in the long term (12). Peri-implant mucositis is an inflammatory disease that affects soft tissues surrounding the implant; it is reversible with proper treatment. Peri-implantitis is a microbial inflammatory disease characterized by the resorption of the supportive bone surrounding the implant in function (13). Gram-negative anaerobic bacteria predominate around the implant sites affected by the disease. While they resemble chronic periodontal infections, they have a more complex microbiological character (14). Predominant species around a peri-implantitis implant are red complex (T. denticola, T. forsythia and $P$. gingivalis) and orange complex bacteria (P. intermedia and $F$. nucleatum) described by Socransky (15).

Apse et al. (16) have identified what they termed "peri-implant crevicular fluid" (PICF), which surrounds the peri-implant sulcus and has properties similar to those of the gingival crevicular fluid. PICF contains several inflammatory mediators, the levels which provide information on the inflammatory state of the tissue, including the activation of mechanisms of bone destruction (17). Prostaglandins, especially prostaglandin E2 (PGE2), are considered as a potent mediator of alveolar bone destruction in periodontitis. A large number of studies reported an increase in PGE2 levels from healthy state to periodontitis (18). Tumor necrosis factor $\alpha$ (TNF- $\alpha$ ) is a proinflammatory cytokine regulating the Gram-negative bacterial response. The TNF- $\alpha$ concentration is an indicator of bacterial load and degree of inflammation (19). In areas where peri-implantitis is active, the presence and activity of osteoclasts are necessary for bone destruction to occur. Osteoclast formation and functions are regulated when the following three TNFs are activated: osteoprotegerin (OPG), receptor activator of nuclear factor kappa B (RANK) and receptor activator of nuclear factor kappa B ligand (RANKL). Soluble receptor activator of nuclear factor- $\mathrm{\kappa B}$ ligand (sRANKL) and OPG have been suggested as molecular determinants of bone resorption. RANKL is a ligand required for osteoclast generation, RANK is the receptor for RANKL, and osteoprotegerin (OPG) is a decoy receptor for RANKL (20) Osteoclast differentiation and activation occur with the binding of RANKL to RANK over the surface of osteoclasts and precursors. OPG, which is a soluble protein of TNF receptors, antagonizes RANK-RANKL interaction and increases bone formation by inhibiting osteoclastogenesis (21). The levels of proinflammatory cytokines, such as PGE2, TNF- $\alpha$, IL-1, IL-6 and RANKL/OPG rates, which allow the determination of osteoclastic activity, change in the case of peri-implantitis (22).

The aim of this study was to evaluate the levels of PGE2, TNF- $\alpha$, RANK, RANKL and OPG in extra short and standard dental implants after a 36- month monitoring period. An additional aim was to to investigate the levels of putative oral pathogens $P$. intermedia, $P$. gingivalis, $F$. nucleatum, $S$. oralis, T. denticola and T. forsythia in submucosal biofilm samples. nu stopu preživljenja kratkih implantata poput onih standardne duljine $(8-10)$.

Nakupljanje mikrobnoga plaka oko implantata glavni je uzrok za njegov gubitak (11). Ako se ne uklone bakterijske naslage, mogu se pojaviti bolesti kao što su periimplantatni mukozitis i periimplantitis, što poslije nekog vremena može rezultirati gubitkom implantata (12). Periimplantatni mukozitis upalna je bolest koja zahvaća meka tkiva oko implantata i reverzibilna je ako se ne provede pravilna terapija. Periimplantitis je bakterijama prouzročena upalna bolest $s$ resorpcijom potporne kosti oko implantata koji je u funkciji (13). Oko implantata zahvaćenih bolešću u biofilmu dominiraju gram-negativne anaerobne bakterije. Iako su slične kroničnim parodontnim infekcijama, te bolesti su mikrobiološki kompleksnije (14). Dominirajuće vrste oko implantata zahvaćenog periimplantitisom dio su crvenoga kompleksa ( $T$. denticola, T. forsythia i P. gingivalis) te narančastoga kompleksa (P. intermedia i F. nucleatum), kako je to opisao Socransky (15).

Apse i suradnici (16) identificirali su ono što su nazvali periimplantatna krevikularna tekućina (PICF) koja se nalazi u periimplantatnom sulkusu i ima svojstva slična onima gingivalne krevikularne tekućine. PICF sadržava nekoliko upalnih medijatora čije razine daju informacije o upalnome stanju tkiva, uključujući i aktivaciju mehanizama destrukcije koštanoga tkiva (17). Prostaglandini, posebno prostaglandin E2 (PGE2), smatraju se snažnim medijatorima destrukcije alveolarne kosti u slučaju parodontitisa. U mnogim istraživanjima ističe se povišena razina PGE2 pri upalnim stanjima kao što je parodontitis (18). Faktor nekroze tumora $\alpha$ (TNF- $\alpha$ ) jest proupalni citokin koji regulira odgovor na gram-negativne mikroorganizme. Koncentracija TNF- $\alpha$ pokazatelj je bakterijskoga opterećenja i stupnja upale (19). U područjima aktivnoga periimplantitisa, prisutnost i aktivnost osteoklasta prijeko je potrebna za razvoj destrukcije kosti. Stvaranje osteoklasta i njihova funkcija regulirani su aktivacijom triju TNF-a: osteoprotegerina (OPG), aktivatora receptora nuklearnoga faktora kappa B (RANK) te liganda aktivatora receptora nuklearnoga faktora kappa $\mathrm{b}$ (RANKL). Topljivi ligand aktivatora receptora nuklearnoga faktora kappa b (sRANKL) i OPG smatraju se molekularnim determinatorima resorpcije kosti. RANKL je ligand potreban za stvaranje osteoklasta, RANK je receptor za RANKL, a OPG je zamjenski receptor za RANKL (20). Diferencijacija i aktivacija osteoklasta aktivira se vezanjem RANKL-a na RANK na površini osteoklasta i njihovih prekursora. OPG, topljivi protein TNF receptora, antagonizira interakciju RANK-a i RANKL-a te povećava stvaranje kosti inhibirajući stvaranje osteoklasta (21). Razine proupalnih citokina kao što su PGE2, TNF- $\alpha$, IL-1, IL-6 te odnos RANKL/OPG koji određuju osteoklastičnu aktivnost, mijenjaju se u slučaju periimplantitisa (22).

Cilj ovog istraživanja bio je procijeniti razine PGE2, TNF- $\alpha$, RANK-a, RANKL-a i OPG-a oko ekstremno kratkih implantata i implantata standardne dužine nakon 36 mjeseci praćenja. Dodatni cilj bio je u uzorcima subgingivalnog biofilma istražiti razine mogućih oralnih patogena $P$. intermedia, P. gingivalis, F. nucleatum, $S$. oralis, T. denticolai i T. forsythia 


\section{Material and methods}

This study involved a prospective, randomized, and splitmouth design clinical trial. A total of 30 extra-short implants (intrabony length $=4 \mathrm{~mm}$ ) and 30 standard implants (intrabony length $\geq 8 \mathrm{~mm}$ ) in 30 periodontally healthy subjects were randomly placed according to the design to receive both implant systems in posterior mandibular edentulous sites.

\section{Patient selection and study design}

This study was carried out by recalling individuals whose bilateral partial tooth losses were treated with implant-supported fixed restorations and whose implants had been functioning for at least 3 years after prosthetic rehabilitation.

The study was conducted according to the principles of the Declaration of Helsinki (Clinical Researches Ethical Board with the 28. 09. 2016 and 2016/009 decision numbered approval). This study is in compliance with the CONSORT Statement. The study protocol was registered with clinicaltrials.gov (registration number NCT04475406) prior to its commencement. Similar methodology and design have been used in the study of other authors (23).

The inclusion criteria for the study were as follows:

1. Sufficient bone height for a 4-mm implant and sufficient bone width for at least a 5.5 -mm implant with no augmentations and no history of periodontitis.

2. Implants placed bilaterally by the same periodontologist (E.Ö.) functioning for at least 3 years

3. Placed implants having the same brand (Straumann SLA Active; Institute Straumann AG, Basel, Switzerland). Patients with cemented implant prosthesis in which standard abutment was used in the mandibular posterior region (24).

Patients with any systemic diseases and smokers with poor oral hygiene (plaque score $>20 \%$ ) and having a parafunctional habit were excluded.

A total of 31 patients met the abovementioned inclusion criteria. One patient did not continue the study. 60 implants were researched in 30 patients ( 16 female and 14 male). The bilateral regions of patients with a standard implant and an extra short implant were grouped into two (25).

Control group: Standard implant, intra-bone length $\geq 8$ $\mathrm{mm}$ (30 implants)

Test group: Extra Short implant, intra-bone length $\leq 4$ mm (30 implants)

\section{Collection of clinical and radiological data}

A single examiner performed all clinical measurements (B.K.), including the presence of bleeding on probing (BOP), probing depth (PD), clinical attachment level (CAL), 3-year survival rate (CSR), and bone loss (BL).

The values of $\mathrm{PD}$ and $\mathrm{BOP}$ were measured from four sites of each implant (mesial, distal, buccal, and lingual) with a Williams type (Hue Friedy, Switzerland) plastic periodontal probe. The PD was recorded as the distance from the base of the peri-implant to the side of the gum in millimeters. BOP was evaluated according to the presence (+) or absence (-) of bleeding within the first $30 \mathrm{~s}$ following the measurement of PD (26).

\section{Materijal i metode}

Ovo istraživanje provedeno je kao prospektivno randomizirano kliničko istraživanje tipa split-mouth. Tridesetero parodontno zdravih pojedinaca dobilo je 30 ekstremno kratkih implantata (intrakoštana dužina $4 \mathrm{~mm}$ ) i 30 standardnih (intrakoštana dužina $\geq 8 \mathrm{~mm}$ ) slučajnim odabirom prema načelu da svaki pacijent u lateralne dijelove donje čeljusti dobije po jedan implantat iz svakog sustava.

\section{Odabir pacijenata i plan istraživanja}

Ovo istraživanje provedeno je na ispitanicima koji su pozvani na ponovne preglede, a imali su obostrani gubitak zuba nadoknađen fiksnim nadomjestcima na implantatima te čiji su implantati bili u funkciji najmanje tri godine.

Istraživanje je bilo u skladu s načelima Helsinške deklaracije (sastanak Etičkoga povjerenstva održan je 28. rujna 2016. godine, a odluka je prihvaćena pod brojem 2016/009) te u skladu s izjavom CONSORT. Još prije početka rada protokol istraživanja postavljen je na stranicu: clinicaltrials.gov pod brojem NCT04475405. Sličnom metodologijom i dizajnom koristili su se i drugi autori u svojim istraživanjima (23).

\section{Kriteriji za uključivanje $u$ istraživanje bili su:}

1. dovoljna visina kost za ugradnju implantata dužine $4 \mathrm{~mm}$ te dovoljna širina grebena, minimalno za implantat širine $5,5 \mathrm{~mm}$, bez augmentacije te bez parodontitisa u anamnezi

2. bilateralno postavljene implantate postavio je isti parodontolog (E. Ö.) i bili su u funkciji najmanje tri godine

3. postavljeni implantati morali su biti istog tipa i od istog proizvođača (Straumann SLA Active, Institute Straumann AG, Basel, Švicarska). Pacijenti su morali imati cementirane nadomjestke u lateralnom dijelu donje čeljusti na standardnim nadogradnjama (24).

Pacijenti sa sistemskim bolestima, pušači i oni s lošom oralnom higijenom (vrijednost plaka $>20 \%$ ) i parafunkcijama isključeni su iz istraživanja.

Navedene kriterije zadovoljio je 31 pacijent, no jedan se nije uključio u istraživanje, pa je pregledano 60 implantata kod 30 pacijenata (16 žena i 14 muškaraca). Lateralni dijelovi donje čeljusti, $s$ po jednim standardnim i jednim kratkim implantatom, podijeljeni su u dvije skupine (25) - kontrolnu (standardni implantat, intrakoštana dužina $\geq 8 \mathrm{~mm}, 30 \mathrm{im}$ plantata) i ispitnu (kratki implantat, intrakoštana dužina $\leq 4$ mm, 30 implantata).

\section{Prikupljanje kliničkih i rendgenskih podataka}

Sva klinička mjerenja obavio je jedan istraživač (B. K.) i to krvarenje pri sondiranju (BOP), mjerenje dubine sondiranja $(\mathrm{PD})$, određivanje kliničke razine pričvrstka (CAL), trogodišnju stopu preživljenja (CSR) i gubitak kosti (BL).

Vrijednosti BOP-a i PD-a izmjerene su na četirima mjestima oko svakog implantata (mezijalno, distalno, bukalno i oralno) plastičnom parodontalnom sondom Williams (HuFriedy, Svicarska). PD je mjeren u milimetrima od dna periimplantatnoga tkiva do ruba mukoze. BOP je određivan dihotomno kao prisutnost (+) ili odsutnost (-) krvarenja unutar 30 sekunda od mjerenja PD-a (26). 
Digital periapical radiographs were taken using the paralleling technique. Similarly, in line with previous studies, sitespecific bone loss around the implants was measured at mesial aspects (27). Therefore at baseline and 36 months after prosthetic loading, the distance between the implant shoulder and first bone contact point was measured.

\section{Collection of PICF and subgingival plaque samples}

Cotton rolls were used to isolate the implants, and they were dried with an air spray. Then, the plaque and soft attachments around the implants were removed. The PICF were obtained from the mesio-buccal aspect of the implants by the paper strips (Oraflow Inc, NY, USA). Paper strips were placed $1-2 \mathrm{~mm}$ in the peri-implant sulcus and left in place for 30 s. Strips contaminated with saliva or blood were discarded.

After collecting the PICF, the supragingival plaque was removed by a sterile scaler and subgingival plaque samples were collected from the mesio-buccal aspect of the implants by a sterile plastic Gracey curette (Hu-Friedy, Switzerland) for $30 \mathrm{~s}$. The samples collected were transferred to sterile Eppendorf tubes containing $200 \mu \mathrm{L}$ of PBS. The tubes were stored at $-80^{\circ} \mathrm{C}$ until the laboratory analyses.

\section{PICF analyses}

PICFs were eluted from the strips by placing them in 200 $\mu \mathrm{L}$ PBS ( $\mathrm{pH}$ 7.2) containing an EDTA-free protease inhibitor (Roche Applied Science, Basel, Switzerland). The total protein content of PICF was quantified using a Qubit Protein Assay kit (Elabscience Biotechnology Co., Ltd, Wuhan, China). according to the manufacturer's instructions.

Commercial enzyme-linked immunosorbent assay kits were used for measuring the levels of TNF- $\alpha$, PGE $_{2}$, RANKL, RANK, and OPG according to the manufacturer's recommendations (Elabscience Biotechnology Co., Ltd, Wuhan, China). The measuring ranges were as follows: TNF- $\alpha, 7.81-$ $500 \mathrm{pg} / \mathrm{mL} ; \mathrm{PGE}_{2}, 31.25-2000 \mathrm{pg} / \mathrm{mL}$; RANKL, 0.16-10 $\mathrm{pg} / \mathrm{mL}$; RANK, $0.16-10 \mathrm{pg} / \mathrm{mL}$; and OPG, $0.16-10 \mathrm{pg} / \mathrm{mL}$. Optical density was measured at $450 \mathrm{~nm}$, and the samples were compared with standards. Biochemical data were measured as the total amount $(\mathrm{pg} / 30 \mathrm{~s})$.

\section{Genomic DNA preparation}

An extraction kit was used according to the manufacturer's instructions to purify the DNA in the collected plaque samples (GF-1 bacterial DNA extraction kit, Vivantis, Malaysia). Standards were used for total DNA in the target bacteria. Genomic DNA was obtained and stored at $4{ }^{\circ} \mathrm{C}$.

\section{Real-time polymerase chain reaction}

Primary probes were determined to define each bacterium and observe the proliferation curves using real-time polymerase chain reaction (PCR) (Table 1). A real-time PCR system (Roche Light Cycler 480 Instrument II, Switzerland) using a master mix (SYBR Green Master Mix; Life Technologies, CA, USA) was used to perform the procedures. PCR cycles were as follows: $10 \mathrm{~min}$ at $95^{\circ} \mathrm{C}, 40$ cycles at $95^{\circ} \mathrm{C}$ for $30 \mathrm{~s}$ and $2 \mathrm{~min}$ at $60^{\circ} \mathrm{C}$. DNA contents were calculated using standard curves.
Digitalne periapikalne rendgenske snimke napravljene su paralelizirajućom tehnikom. Slično, u skladu s ranijim istraživanjima, izmjeren je gubitak kosti oko implantata na mezijalnoj strani (27) na početku opterećenja i 36 mjeseci poslije. Mjerena je i udaljenost između vrata implantata i prvoga kontakta kosti i površine implantata.

\section{Uzimanje uzoraka PICF-a i subgingivalnog biofilma}

Implantati su izolirani vaterolicama i posušeni komprimiranim zrakom. Zatim je uklonjen plak i mekane naslage oko implantata. PICF je papirnatim štapićima (Oraflow Inc., NY, $\mathrm{SAD}$ ) uzet $s$ meziobukalne strane implantata. Papirnati štapići postavljeni su od 1 do $2 \mathrm{~mm}$ u periimplantatni sulkus te ostavljeni 30 sekunda da upiju tekućinu. Odbačeni su uzorci kontaminirani slinom ili krvlju.

Nakon prikupljanja PICF-a uklonjen je supragingivalni plak sterilnim strugačem te su tijekom 30 sekunda uzimani njegovi uzorci $s$ meziobukalne površine implantata sterilnom plastičnom Graceyjevom kiretom (Hu-Friedy, Švicarska). Prikupljeni uzorci stavljeni su u sterilne Eppendorfove epruvete s $200 \mu \mathrm{L} \mathrm{PBS}$-a. Do analize u laboratoriju čuvani su na temperaturi od $-80^{\circ} \mathrm{C}$.

\section{Analiza PICF-a}

PICF je izdvojen iz štapića uranjanjem u $200 \mu \mathrm{L}$ PBS-a $(\mathrm{pH} 7,2)$ koji sadržava inhibitor proteaze bez EDTA-e (Roche Applied Science, Basel, Švicarska). Ukupan sadržaj proteina iz PICF-a kvantificiran je s pomoću kita Qubit Protein Assay (Elabscience Biotechnology Co. Ltd., Wuhan, Kina) prema uputama proizvođača.

Za mjerenje razina TNF- $\alpha$, PGE, RANKL-a, RANK-a i OPG-a korišteni su komercijalni kitovi ELISA (Elabscience Biotechnology Co. Ltd., Wuhan, Kina). Rasponi mjerenja bili su: TNF- $\alpha-7,81$ do $500 \mathrm{pg} / \mathrm{mL}$; PGE $_{2}-31,25$ do 2000 $\mathrm{pg} / \mathrm{mL}$; RANKL - 0,16 do $10 \mathrm{pg} / \mathrm{mL}$; RANK - 0,16 do 10 $\mathrm{pg} / \mathrm{mL}$; OPG - 0,16 do10 pg/mL. Optička gustoća mjerena je pri $450 \mu \mathrm{m}$, a uzorci su uspoređivani sa standardima. Biokemijski podatci mjereni su kao ukupna količina (pg/30 s).

\section{Priprema genomskoga DNK-a}

Korišten je ekstrakcijski komplet za pročišćivanje DNK iz uzetih uzoraka prema uputi proizvođača (GF-1 bacterial DNA extraction kit, Vivantis, Malezija). Standardi su korišteni za ukupni DNK ciljanih bakterija. Genomski DNK dobiven je i čuvan na $4^{\circ} \mathrm{C}$.

\section{PCR u stvarnom vremenu (real-time)}

Određene su primarne sonde kako bi se definirala svaka bakterija i vidjele proliferacijske krivulje korištenjem RTPCR-a (tablica 1.). Za to je upotrijebljen sustav RT PCR (Roche Light Cycler 480 Instrument II, Śvicarska) s glavnom mješavinom (SYBR Green Master Mix, Life Technologies, CA, SAD). Ciklusi PCR-a bili su: 10 minuta na $95^{\circ} \mathrm{C}, 40$ ciklusa na $95^{\circ} \mathrm{C}$ tijekom 30 sekunda i 2 minute na $60^{\circ} \mathrm{C}$. Sadržaj DNK izračunat je s pomoću standardnih krivulja. 
Table 1 Primers/probes and DNA sequences of bacterial species

Tablica 1. Primeri/probe i sekvencije DNK bakterijskih vrsta

1 Total bacteria

Forward: 5'-CGCTAGTAATCGTGGATCAGAATG-3'

Reverse: 5'-TGTGACGGGCGGTGTGTA-3'

Probe: 5'-FAM-CACGGTGAATACGTTCCCGGGC-TAMRA-3'

\section{P. intermedia}

Forward: 5'- CGG TCT GTT AAG CGT GTT GTG-3'

Reverse: 5'- CAC CAT GAA TTC CGC ATA CG-3'

Probe: 5'-FAM-TGG CGG ACT TGA GTG CAC GC-TAMRA-3'

\section{T. forsythia}

Forward: 5'-GGG TGA GTA ACG CGT ATG TAA CCT-3'

Reverse: 5'-ACC CAT CCG CAA CCA ATA AA-3'

Probe: 5'-FAM-CCC GCA ACA GAG GGA TAA CCC GG-TAMRA-3'

4. T. denticola

Forward: 5'-GTTGTTCGGAATTATTGG-3'

Reverse: 5'- GATTCAAGTCAAGCAGTA-3'

Probe: 5'-Cy5.5-TCACACCAGGCTTACC-3'-BHQ 2

\section{F. nucleatum}

Forward: 5'-GGCTTCCCCATCGGCATTCC-3'

Reverse: 5'-AATGCAGGGCTCAACTCTGT-3'

Probe: 5'-Cy5-TCCGCTTACCTCTCCAG -3'- BHQ 2

\section{6. $P$. gingivalis}

Forward: 5'-CTGCGTATCCGACATATC-3'

Reverse: 5'-GGTACTGGTTCACTATCG-3'

Probe: 5'-Texas Red ACCATAGACGACGGAGCACC-3'-BHQ 2

7. Streptococcus oralis glucosyltransferase (gtfR) gene

Forward: 5'-GCGTAAGGCAGACAAGAAGTA--3

Reverse: 5'-CCATAGTAGACCCGAGTGATAGA -3'

Probe: 5' FAM-ATCCCAACTGCTCATGCCCTCAT - $3^{\prime}$-TAMRA

\section{Statistical analysis}

The SPSS 19.0 (IBM Inc., IL, USA) was used for the statistical analyses. To determine normally distribution, Kolmogorov-Smirnov and Shapiro-Wilk tests were used. The level of significance was used as 0.05 while commenting on the results.

The independent-samples $t$ test was used for normally distributed variables, while the nonparametric Mann-Whitney $U$ test was used for the variables which were not normally distributed. The chi-square analysis was used while examining the relationships between the groups of nominal variables. The survival rate (CSR) was calculated according to the number of short and standard implants placed.

\section{Results}

Sixty implants were randomly placed into 30 periodontally healthy subjects ( 16 women and 14 men) with a mean age of 35-66 years and bilaterally posterior mandibular edentulous sites using the split-mouth design (Table 2). The mean \pm SD bone resorption based on the radiographs was $0.00 \pm$ 0.50 in the extra-short implant group and $0.33 \pm 0.60$ in the standard-length implant group with no significant difference between the groups $(P>0.05)$ (Table 3). A 3-year implant survival rate was $100 \%$ in both implants. PD values (mean SD) of both groups were within healthy limits (PD: $1.99 \pm$

\section{Statistička analiza}

Statistička analiza obavljena je u programu SPSS 19,0 (IBM Inc., IL, SAD). Za normalnost distribucije korišteni su Kolmogorov-Smirnovljev i Shapiro-Wilkov test. Razina značajnosti određena je na 0,05 tijekom komentiranja rezultata.

Za normalno distribuirane varijable korišten je t-test nezavisnih uzoraka, a za varijable koje nisu imale normalnu distribuciju neparametrijski Mann-Whitneyjev $U$ test. Za analizu odnosa između skupina nominalnih varijabli korišten je hi-kvadrat test. Stopa preživljavanja (CSR) izračunata je prema broju postavljenih kratkih i standardnih implantata.

\section{Rezultati}

Trideset pacijenata slučajnim je odabirom dobilo $60 \mathrm{im}$ plantata (16 žena i 14 muškaraca). Srednja dob bila je od 35 do 66 godina. Implantati su ugrađivani u lateralne dijelove donje čeljusti prema načelu split-mouth (tablica 2.). Srednja vrijednost resorpcije kosti na temelju rendgenskih snimaka iznosila je 0,00 $\pm 0,50$ kod kratkih implantata i 0,33 $\pm 0,60$ kod standardnih implantata - nije bilo statistički značajne razlike ( $>$ > 0,05, tablica 3). Trogodišnja stopa preživljenja u objema skupinama iznosila je $100 \%$, a vrijednosti PD-a bile su unutar zdravih granica $(1,99 \pm 0,14$ vs. $3,03 \pm 0,20$ na po- 
Table 2 Comparison of probing depth and clinical attachment level according to implant groups

Tablica 2. Usporedba dubina sondiranja i kliničke razine pričvrstka između skupina implantata

\begin{tabular}{|c|c|c|c|c|c|c|}
\hline & & Group & $n$ & Mean & SD & $P$ \\
\hline \multirow{4}{*}{ Probing depth (mm) } & \multirow{2}{*}{ Baseline } & Test & 30 & 1.99 & 0.14 & \multirow{2}{*}{0,12} \\
\hline & & Control & 30 & 3.03 & 0.20 & \\
\hline & \multirow{2}{*}{ 3-year } & Test & 30 & 2.20 & 0.21 & \multirow{2}{*}{0,24} \\
\hline & & Control & 30 & 3.32 & 0.30 & \\
\hline \multirow{4}{*}{ Clinical attachment level (mm) } & \multirow{2}{*}{ Baseline } & Test & 30 & 2.10 & 0.05 & \multirow{2}{*}{0,22} \\
\hline & & Control & 30 & 3.89 & 0.32 & \\
\hline & \multirow{2}{*}{ 3-year } & Test & 30 & 2.30 & 0.15 & \multirow{2}{*}{0,43} \\
\hline & & Control & 30 & 3.50 & 0.50 & \\
\hline
\end{tabular}

Table 3 Mean radiographic Marginal Bone Loss \pm SD $(\mathrm{mm})$ at 3-year examination

Tablica 3. Srednji rendgenski marginalni gubitak kosti i standardna devijacija nakon tri godine

\begin{tabular}{c|c|c|c|c|}
\hline MBL & Test & Control & \multicolumn{1}{c|}{$\boldsymbol{p}$} \\
Mesial & $0.11 \pm 0.2$ & $0.25 \pm 0.5$ & 0,25 \\
\hline Distal & $0.14 \pm 0.7$ & $0.43 \pm 0.7$ & 0,32 \\
\hline
\end{tabular}

Table 4 Comparison of bleeding on probing according to implant groups (\%)

Tablica 4. Usporedba krvarenja pri sondiranju između skupina (\%)

\begin{tabular}{c|c|c} 
& Baseline & \\
Test & $3 \%$ & $4 \%$ \\
\hline Control & $2 \%$ & $2 \%$ \\
\hline Significance & 0,08 & 0,15 \\
\hline
\end{tabular}

0.14 vs. $3.03 \pm 0.20$ at baseline and $2.20 \pm 0.21$ vs. $3.32 \pm$ 0.30 at 36 months in Test group and Control group, respectively). BOP scores are presented in Table 4. BOP values (full mouth) of both groups were low with no significant difference (3\% vs. $4 \%$ at baseline and $2 \%$ vs $2 \%$ at 36 months in Test group and Control group, respectively). The BOP means \pm SDs for both groups were below $10 \%$ with no significant difference between the groups (Table 4). PI scores of both groups were measured below 2 both at baseline and at 36 months. CAL values of both groups were within healthy limits also, and there was no significant change in CAL level at 36 months (CAL: 2.10 vs. 3.89 at baseline and 2.30 vs. 3.50 at 36 months in Test group and Control group, respectively).

\section{Immunological results}

When the samples taken from extra short and long implants functioning for 3 years were evaluated, no statistically significant difference was found between the groups in terms of total amounts of PGE, TNF- $\alpha(P>0.05)$ (Table 3). The total amounts of RANKL, RANK and OPG and the RANKL/OPG ratio in PISF samples in each group are presented in Table 3. No statistically significant difference was found between the groups.

\section{Microbiological results}

Submucosal biofilm samples were assessed using qPCR for six individual bacterial species and for total bacterial counts (Table 4). When microbial plaque samples taken from functioning implants were evaluated, the amounts of $P$. intermedia, F. nucleatum, T. denticola, T. forsythia, P. gingivalis and $S$. oralis did not reveal statistically significant differences between the groups $(P>0.05)$ (Table 4$)$. četku te $2,20 \pm 0,21$ vs. $3,32 \pm 0,30$ poslije 36 mjeseci). Vrijednosti BOP-a nalaze se u tablici 4 . Vrijednosti BOP-a za cijela usta bile su niske, bez značajne razlike (3\% vs. $4 \%$ na početku i $2 \%$ vs. $2 \%$ poslije 36 mjeseci). Srednje vrijednosti BOP-a za obje skupine bile su manje od $10 \%$ te između njih nije bilo značajne razlike (tablica 4.). Izmjerene vrijednosti PICF-a za obje skupine bile su ispod dva na početku i nakon 36 mjeseci. Vrijednosti CAL-a za obje skupine bile su također unutar zdravih granica te nije bilo značajnih promjena u njihovim vrijednostima poslije 36 mjeseci $(2,10$ vs. 3,89 na početku i 2,30 vs. 3,50 poslije 36 mjeseci).

Imunološki rezultati

U analizi uzoraka kratkih i standardnih implantata koji su bili tri godine $\mathrm{u}$ funkciji nije pronađena statistički značajna

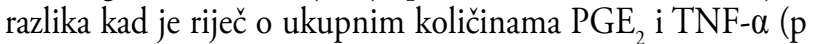
$>0,05)$ (tablica 3.). Ukupne vrijednosti RANKL-a, RANKa i OPG-a te omjer RANKL/OPG u uzorcima PICF-a prikazani su u tablici 3. Nije bilo statistički značajne razlike između skupina.

\section{Mikrobiološki rezultati}

Uzorci submukoznoga biofilma procjenjivani su s pomoću qPCR-a za šest pojedinačnih bakterijskih vrsta (tablica 4.). Nije bilo statistički značajne razlike u količini bakterija oko dviju različitih vrsta implantata koji su tri godine u funkciji. Ispitivane su količine sljedećih bakterija: P. intermedia, $F$. nucleatum, T. denticola, T. forsythia, P. gingivalis i $S$. oralis ( $\mathrm{p}$ $>0,05$, tablica 4.). 
Table 5 Comparison of immunological results according to implant groups after 3 years.

Tablica 5. Usporedba imunoloških rezultata između skupina nakon tri godine

\begin{tabular}{|c|c|c|c|c|}
\hline & Group & $n$ & Mean \pm SD & $P$ \\
\hline \multirow{2}{*}{ PGE2 (ng/30s) } & Test & 30 & $26.25 \pm 4.94$ & \multirow{2}{*}{0.90} \\
\hline & Control & 30 & $25.94 \pm 6.17$ & \\
\hline \multirow{2}{*}{ TNF ALFA (ng/30 s) } & Test & 30 & $33.96 \pm 2.5$ & \multirow{2}{*}{0.92} \\
\hline & Control & 30 & $34.61 \pm 1.85$ & \\
\hline \multirow{2}{*}{ OPG (ng/30s) } & Test & 30 & $1.60 \pm 0.02$ & \multirow{2}{*}{0.91} \\
\hline & Control & 30 & $1.60 \pm 0.02$ & \\
\hline \multirow{2}{*}{ RANKL (ng/30 s) } & Test & 30 & $0.80 \pm 0.02$ & \multirow{2}{*}{0.72} \\
\hline & Control & 30 & $0.81 \pm 0.03$ & \\
\hline \multirow{2}{*}{ RANKL/OPG } & Test & 30 & $0.50 \pm 0.01$ & \multirow{2}{*}{0.479} \\
\hline & Control & 30 & $0.51 \pm 0.01$ & \\
\hline \multirow{2}{*}{ RANK (ng/30 s) } & Test & 30 & $0.59 \pm 0.17$ & \multirow{2}{*}{0.536} \\
\hline & Control & 30 & $0.63 \pm 0.09$ & \\
\hline
\end{tabular}

\begin{tabular}{|c|c|c|c|c|c|}
\hline & Group & $n$ & Mean & SD & $P$ \\
\hline \multirow{2}{*}{ F. nucleatum } & Test & 30 & $2.7 \times 10^{4}$ & $2.4 \times 10^{4}$ & \multirow{2}{*}{0.094} \\
\hline & Control & 30 & $2.6 \times 10^{4}$ & $2.6 \times 10^{4}$ & \\
\hline \multirow{2}{*}{ T. forsytia } & Test & 30 & $5.3 \times 10^{3}$ & $3.1 \times 10^{3}$ & \multirow{2}{*}{0.06} \\
\hline & Control & 30 & $6.7 \times 10^{3}$ & $4.2 \times 10^{3}$ & \\
\hline \multirow{2}{*}{ P. intermedia } & Test & 30 & $0.9 \times 10^{3}$ & $1.3 \times 10^{2}$ & \multirow{2}{*}{0.19} \\
\hline & Control & 30 & $1.1 \times 10^{3}$ & $1.8 \times 10^{2}$ & \\
\hline \multirow{2}{*}{ P. gingivalis } & Test & 30 & $2.4 \times 10^{4}$ & $1.1 \times 10^{4}$ & \multirow{2}{*}{0.73} \\
\hline & Control & 30 & $3.9 \times 10^{4}$ & $2.7 \times 10^{4}$ & \\
\hline \multirow{2}{*}{ S. oralis } & Test & 30 & $1.4 \times 10^{2}$ & $2.7 \times 10^{3}$ & \multirow{2}{*}{0.161} \\
\hline & Control & 30 & $4.2 \times 10^{2}$ & $1.3 \times 10^{3}$ & \\
\hline \multirow{2}{*}{ T. denticola } & Test & 30 & $5.4 \times 10^{4}$ & $3.1 \times 10^{4}$ & \multirow{2}{*}{0.094} \\
\hline & Control & 30 & $4.4 \times 10^{4}$ & $5.3 \times 10^{4}$ & \\
\hline
\end{tabular}

\section{Discussion}

The present randomized, clinical trial showed that 36 months after the prosthesis loading, peri-implant bone loss surrounding short- and standard-length implants was comparable. Clinical peri-implant parameters (PD, CAL, BOP, and CSR), in terms of the levels of total PGE2, RANK, RANKL, OPG and TNF- $\alpha$, RANKL/OPG ratio, and microbiological findings both types of implants were similar and showed similar favorable results.

The RANK-RANKL-OPG system is vital in the bone remodeling mechanism in the bone and implant interface. RANK/RANKL/OPG interaction, TNF- $\alpha$, and $\mathrm{PGE}_{2}$ are components of a complex process, and systemic health, hormonal and metabolic states. (28). Previous studies showed no differences between standard and short implants with a rough surface in terms of BL. The present study also demonstrated no significant difference in total amounts of RANKL, RANK, OPG, TNF- $\alpha$, and PGE between the groups (29).

Lamster et al. (30) stated that the total amount of gingival crevicular fluid was a better indicator compared with concentration. The concentration is directly affected by sample volume, and the total amount provides more objective results. In this study, the total amount of PICF was evaluated and found to be similar between the groups.

\section{Rasprava}

U ovom randomiziranom kliničkom istraživanju pokazalo se da se 36 mjeseci poslije opterećenja protetičkom radom može usporediti gubitak periimplantatne kosti oko kratkih i standardnih implantata. Klinički periimplantatni parametri (PD, CAL, BOP i CSR), ukupne razine PGE, TNF- $\alpha$, RANK-a, RANKL-a, OPG-a i omjer RANKL/OPG te mikrobiološki nalazi obiju vrsta implantata bili su usporedivi i povoljni.

Sustav RANK-RANKL-OPG važan je za mehanizam remodelacije kosti na spoju kosti i implantata. Interakcija RANK/RANKL/OPG, TNF- $\alpha$ i PGE, komponente su kompleksnoga procesa, sustavnog zdravlja te hormonalnog i metaboličkog stanja (28). U dosadašnjim istraživanjima autori nisu uočili razlike između kratkih i standardnih implantata kad je riječ o BL-u. Naše istraživanje također nije pokazalo značajne razlike između skupina u ukupnoj količini RANKLa, RANK-a, OPG-a, TNF- $\alpha$ i PGE $_{2}$ (29).

Lamster i suradnici (30) ustanovili su da je ukupna količina gingivalne krevikularne tekućine bolji indikator nego koncentrat. $\mathrm{Na}$ koncentrat izravno utječe volumen uzorka, a ukupna količina daje objektivniji rezultat. U ovom istraživanju procjenjivana je ukupna količina PICF-a te se pokazalo da je slična u objema skupinama. 
Bacterial colonization surrounding implants was observed sometime after mouth penetration. The authors of previous studies have noticed that during implantation, the microflora in the oral cavity was also affected. In addition, periodontal pathogens were often present in the implants of patients who had a history of periodontal disease (31). The present study suggested that a low abundance of periodontal pathogens might be related to the absence of periodontitis history in patients. In addition, a decrease in the presence of bacteria was related to the position of the implant in the bone (32). In the present study, the bacteria load was relatively low in all implants placed in the bone.

The results of recent studies indicated that the survival rates of the 6-mm short, micro-rough implants were similar to those of standard-length implants $(33,34)$. The CSR\% range for 6-mm short implants $(93.7 \%-97.6 \%)$ was also found to be compatible with long-term survival rates of standard-length implants published in previous studies $(35,36)$. In our study, neither group experienced enhanced bone resorption or pathological destruction.

No consensus has been reached on the performance of short implants compared with standard implants (37). Short implants are associated with higher failure rates than standard-length implants because of their reduced contact with bone and high primary stability causing decreased osseointegration. In addition, the high crown-to-root ratio may cause increased occlusal stresses on the periimplant bone. $(38,39)$. However, a large number of studies showed similar success rates with standard implants (40). In the study of Guarni et al. short and standard implants had similar survival rates, MBL, and peri-implant soft tissue conditions over the observation period of 3 years (41). Studies conducted in recent years have emphasized the advantages of short implants (2, $5,8,10)$.

One of the limitations of this study was a small sample size. This might be the reason why the difference between the total amounts of RANKL, RANK, OPG, TNF- $\alpha$, and PGE2 and the abundance of $F$. nucleatum, P. gingivalis, $P$. intermedia, S. oralis, T. forsythia and T. denticola between the groups was not significant. Another limitation was that it was not possible to distinguish between the numbers of living or nonliving bacteria because the bacterial study was conducted with PCR.

When bilaterally placed extra short and standard implants were compared, similar clinical, immunological, and microbiological results with standard implants were obtained in short implant sites after a 3 -year functioning period.

\section{Conclusions}

In conclusion, the present study showed that the level of PGE, TNF- $\alpha$, RANKL, RANK, OPG, and RANKL/OPG ratio in PICF was similar between standard $(\geq 8 \mathrm{~mm})$ and extra short $(4 \mathrm{~mm})$ implants after a 36-month monitoring period. Both implant types had favorable clinical results with similar osteoimmunological and microbiological responses of the peri-implant tissues. Within the limitations, we can say that placement of extra-short implants $(4 \mathrm{~mm})$ is an option
Bakterijska kolonizacija implantata uočena je neko vrijeme nakon otvaranja implantata. Autori ranijih istraživanja primijetili su da se tijekom ugradnje implantata događaju promjene u oralnoj mikroflori. Dodatno su parodontni patogeni prisutni oko implantata pacijenata koji su prije imali parodontnu bolest (31). Naše istraživanje pokazalo je da bi mala količina parodontnih patogena mogla biti povezana s činjenicom da pacijenti nisu bolovali od parodontitisa. Istaknimo da je smanjena prisutnost bakterija povezana s položajem implantata u kosti (32). Naše istraživanje pokazalo je razmjerno malo bakterijsko opterećenje oko svih implantata.

Rezultati nedavnih istraživanja pokazali su da se stope preživljenja kratkih (6 milimetarskih) implantata s mikronepravilnostima na površini mogu usporediti sa stopama preživljenja standardnih implantata tijekom duljeg razdoblja $(93,7-97,6 \%)(35,36)$. U našem istraživanju ni u jednoj skupini nije zabilježena pojačana resorpcija kosti ili patološka destrukcija.

Nema jedinstvenoga stajališta o ishodu kratkih implantata u usporedbi sa standardnima (37). Kratki se implantati povezuju $s$ većim stopama neuspjeha nego oni standardne dužine zbog smanjenoga kontakta $s$ koštanim tkivom i visokom primarnom stabilnošću koja uzrokuje smanjenu oseointegraciju. Dodatno, veliki nerazmjer u omjeru krune i korijena može potaknuti okluzalni stres i opterećenje periimplantatne kosti $(38,39)$. Pa ipak, u mnogobrojnim istraživanjima opisane su slične stope uspješnosti za kratke i standardne implantate (40). Guarni i suradnici pokazali su slične stope uspješnosti kratkih i standardnih implantata i razine MBL-a te stanja periimplantatnoga mekanoga tkiva tijekom trogodišnjega praćenja (41). U istraživanjima provedenima posljednjih godina ističu se prednosti kratkih implantata $(2$, $5,8,10)$.

Jedno od ograničenja u našem istraživanju bio je malen uzorak. To bi mogao biti razlog zašto nisu zabilježene značajne razlike između ukupnih količina RANKL-a, RANKa, OPG-a, TNF- $\alpha$ i PGE 2 te brojnost mikroorganizama. Još jedno ograničenje jest to što se nije moglo raspoznati žive od neživih bakterija zato što je analiza provedena PCR metodom.

Obostrano postavljeni kratki i standardni implantati pokazali su slične kliničke, mikrobiološke i imunološke rezultate nakon tri godine u funkciji.

\section{Zaključci}

$\mathrm{Na}$ kraju, naše je istraživanje pokazalo da su razine PGE, TNF- $\alpha$, RANKL-a, RANK-a, OPG-a te omjer OPG/RANKL u PICF-u slične kod standardnih $(\geq 8 \mathrm{~mm})$ i kratkih $(\leq 4$ $\mathrm{mm}$ ) implantata nakon 36 mjeseci praćenja. $S$ objema vrstama implantata postignuti su povoljni klinički rezultati i slični osteoimunološki i mikrobiološki odgovori periimplantatnoga tkiva. Unutar ograničenja našega istraživanja možemo reći da je postavljanje kratkih $(4 \mathrm{~mm})$ implantata alternativa 
to standard-length implants in treating patients with an atrophic posterior mandibular arch as observed during a 3-year follow-up examination.

In patients that require bone augmentation, extra-short implants can be an alternative to standard-length implants. It was observed that with 4-mm implants, the rehabilitation of posterior atrophic mandible was faster and cheaper.

The present results should be verified by additional studies that include longer follow-up periods. Additionally, more samples are required to validate the findings of the present study.

\section{Funding}

None

\section{Conflict of interest}

The authors declare that they have no conflict of interests.

Author's Contribution: B.K. - Data curation, formal analysis, investigation, methodology, software, supervision, validation, writing-orig inal draft, writing-review editing; E.0. - Conceptualization, methodology project administration, data curation, resources, visualization. onima standardne dužine kod pacijenata s atrofičnim lateralnim dijelovima donje čeljusti. To je zaključeno nakon trogodišnjega praćenja.

Kod pacijenata kojima je potrebna augmentacija koštanoga tkiva, kratki implantati mogu biti alternativa standardnima. Pokazalo se da implantati dugi 4 milimetra osiguravaju bržu i jeftiniju rehabilitaciju atrofičnih lateralnih dijelova donje čeljusti.

Naše istraživanje potrebno je potvrditi duljim praćenjem. Dodatno, potrebno je više uzoraka koji bi potvrdili nalaze iz ovog istraživanja.

\section{Financiranje}

Nije ga bilo.

\section{Sukob interesa}

\section{Autori nisu bili u sukobu interesa.}

Doprinos autora: B. K. - briga o podatcima, formalna analiza, istraživanje, metodologija, software, nadzor, validacija, pisanje izvornoga teksta, uređivanje teksta; E. 0. - smišljanje, metodologija, administracija projekta, briga o podatcima, izvori, vizualizacija.
Sažetak

Cilj: Željelo se procijeniti razine TNF- $\alpha$, PGE $_{2}$, RANKL-a, RANK-a i OPG-a, biljega gubitka kosti oko implantata u periimplantatnoj krevikularnoj tekućini oko standardnih i ekstremno kratkih implantata. Nadalje, ispitivane su i razine mogućih oralnih patogena u uzorcima submukoznog biofilma. Materijal i metoda: Implantati su podijeljeni u dvije skupine prema dužini - na standardne $(\geq 8 \mathrm{~mm})$ i ekstremno kratke (4 mm). Ispitano je ukupno 60 implantata ugrađenih kod 30 sudionika. Mjerena je dubina sondiranja (PD), klinička razina pričvrstka (CAL), krvarenje pri sondiranju (BOP), trogodišnja stopa preživljenja (CSR) i gubitak kosti (BL). Rezultati: Između skupina nije bilo statistički značajne razlike u vrijednostima PD-a, CAL-a, BOP-a, CSR-a i BL-a ( $p>0,05)$. Ukupne vrijednosti TNF- $\alpha, P E_{2}$, RANKLa, RANK-a i OPG-a te omjer RANKL/OPG nisu bili statistički značajni između skupina ( $p>0,05)$. Brojnost mikroorganizama $F$. nucleatum, $T$. forsythia, $P$. intermedia, $P$. gingivalis, $S$. oralis i $T$. denticola također je uspoređena, no rezultati nisu bili statistički značajni $(p>0,05)$. Zaključak: Prema rezultatima dobivenima u ovom istraživanju vrijednosti TNF- $\alpha, P_{\text {PGE}}$, RANKL-a, RANK-a i OPG-a te omjer RAN$\mathrm{KL} / \mathrm{OPG}$ u periimplantatnoj krevikularnoj tekućini i mikrobiološki parametri u submukoznom biofilmu slični su i oko standardnih ( $\geq 8 \mathrm{~mm}$ ) i oko ekstremno kratkih $(4 \mathrm{~mm})$ implantata. Zato se čini da dužina implantata ne utječe na gubitak kosti i razinu osteoimunoloških i mikrobioloških biljega u periimplantatnom tkivu te na stopu preživljenja.
Zaprimljen: 14. travnja 2021.

Prihvaćen: 15. srpnja 2021.

Adresa za dopisivanje

Bilge Karcl

Sveučilište Alanya Aladdin Keykubat Fakultet dentalne medicine Zavod za parodontologiju Alanya, Antalija, Turska tel. +902425106140 faks: +9024251061 44 bilge0013@hotmail.com

MeSH pojmovi: dentalna implantacija; oseointegracija; spoj kosti i implantata; biofilm Ključne riječi: dentalni implantati, imunologija, mikrobiologija

\section{References}

1. Chappuis V, Araújo MG, Buser D. Clinical relevance of dimensional bone and soft tissue alterations post- extraction in esthetic sites. Periodontology 2000. 2017 Feb;73(1):73-83.

2. Rosen PS, Sahlin H, Seemann R, Rosen AS. A 1-7 year retrospective follow-up on consecutively placed 7-mm-long dental implants with an electrowetted surface. Int J Implant Dent. 2018 Aug; 4:24.

3. Jelušić D, Puhar I, Plančak D. Assessment of implant stability following sinus lift procedures with different grafting materials. Acta Stomatol Croat. 2014 Mar;48(1):25-32.

4. Lee SA, Lee CT, Fu MM, Elmisalati W, Chuang SK. Systematic review and meta-analysis of randomized controlled trials for the management of limited vertical height in the posterior region: short implants ( 5 to $8 \mathrm{~mm}$ ) vs longer implants $(>8 \mathrm{~mm})$ in vertically augmented sites. Int J Oral Maxillofac Implants. Sep-Oct 2014;29(5):1085-97.

5. Nisand D, Renouard F. Short implant in limited bone volume. Periodontol 2000. 2014 Oct;66(1):72-96.

6. Carelli S, Passaretti A, Petroni G, Zanza A, Testarelli L, Cicconetti A. Five Years Follow-up of Short Implants Placed in Atrophic Maxilla with Simultaneous Sinus Floor Transcrestal Elevation. Acta Stomatol Croat. 2021 Jun;55(2):177-185.
7. Anitua E. Immediate Loading of Short Implants in Posterior Maxillae: Case Series. Acta Stomatol Croat. 2017 Jun;51(2):157-162.

8. Sahrmann P, Naenni N, Jung RE, Held U, Truninger T, Hämmerle CHF et al. Success of 6-mm implants with single-tooth restorations: A 3-year Randomized Controlled Clinical Trial. J Dent Res. 2016 Jun;95(6):623-8.

9. Schiegnitz E, Kammerer PW, Sagheb K, Wendt AJ, Pabst A, AlNawas $B$ et al. Impact of maxillary sinus augmen- tation on oral health-related quality of life. Int I Implant Dent. 2017 Dec;3(1):10.

10. Schincaglia GP, Thoma DS, Haas R, Tutak M, Garcia A, Taylor TD et al. Randomized controlled multicenter study comparing short dental implants (6 $\mathrm{mm}$ ) versus longer dental implants (11-15 $\mathrm{mm})$ in combination with sinus floor elevation procedures. Part 2: Clinical and radiographic outcomes at 1 year of loading. J Clin Periodontol. 2015 Nov;42(11):1042-51.

11. Van Assche N, Pittayapat P, Jacobs R, Pauwels M, Teughels W, Quirynen M. Microbiological outcome of two screw- shaped titanium implant systems placed following a split-mouth randomised protocol, at the 12th year of follow- up after loading. Eur J Oral Implantol. Summer 2011;4(2):103-16.

12. Lang N, Berglundh T, Working Group 4 Of Seventheuropean Workshop On Periodontology. Periimplantdiseases: where are 
we now?-Consensus of the Seventh Euro-pean Workshop on Periodontology. J Clin Periodontol 2011 Mar;38 Suppl 11:178-81.

13. Zitzmann NU, Berglundh T. Definition and prevalence of peri-implant diseases. J Clin Periodontol. 2008 Sep;35 Suppl 8:S286-91.

14. Mombelli A, Decaillet F. The characteristics of biofilms in peri-implant disease. J Clin Periodontol. 2011 Mar;38 Suppl 11:S203-13.

15. Socransky SS, Haffajee AD, Cugini MA, Smith C, Kent RL Jr. Microbial complexes in subgingival plaque. J Clin Periodontol. 1998 Feb;25(2):134-44.

16. Apse P, Ellen RP, Overall CM, Zarb GA. Microbiota and crevicular fluid collagenase activity in the osseointegrated dental implant sulcus: a comparison of sites in edentulous and partially edentulous patients. J Periodontal Res. 1989 Mar;24(2):96-105.

17. Kaklamanos EG, Tsalikis L. A review on peri-implant crevicular fluid assays potential in monitoring and predicting peri-implant tissue responses. J Int Acad Periodontol. 2002 Apr;4(2):49-59.

18. Kumar AK, Reddy NR, Babu M, Kumar PM, Reddy VS, Chavan CV. Estimation of prostaglandin E2 levels in gingival crevicular fluid in periodontal health, disease and after treatment. Contemp Clin Dent. 2013 Jul;4(3):303-6.

19. Graves DT, Oskoui M, Volejnikova S, Naguib G, Cai S, Desta T, et al. Tumor necrosis factor modulates fibroblast apoptosis, PMN recruitment, and osteoclast formation in response to $P$. gingivalis infection. J Dent Res. 2001 Oct;80(10):1875-9.

20. Yasuda H. Discovery of the RANKL/RANK/OPG system. J Bone Miner Metab. 2021 Jan;39(1):2-11.

21. Teitelbaum SL, Ross FP. Genetic regulation of osteoclast development and function. Nat Rev Genet. 2003 Aug;4(8):638-49.

22. Duarte PM, de Mendonça AC, Máximo MB, Santos VR, Bastos MF, Nociti Júnior FH. Differential cytokine expressions affect the severity of peri-implant disease. Clin Oral Implants Res. 2009 May;20(5):514-20.

23. Öztürk VÖ, Emingil G, Bostanci N, Belibasakis GN. Impact of implant-abutment connection on osteoimmunological and microbiological parameters in short implants: a randomized controlled clinical trial. Clin Oral Implants Res. 2017 Sep;28(9):e111-e120.

24. Misch CE, Steignga J, Barboza E, Misch-Dietsh F, Cianciola LJ, Kazor C. Short dental implants in posterior partial edentulism: multicenter retrospective 6-year case series study. J Periodontol. 2006 Aug;77(8):1340-7.

25. Renouard F, Nisand D. Impact of implant length and diameter on survival rates. Clin Oral Implants Res. 2006 Oct;17 Suppl 2:S35 51.

26. Muhlemann HR, Son S. Gingival sulcus bleeding--a leading symptom in initial gingivitis. Helv Odontol Acta. 1971 Oct;15(2):10713.

27. Rossi F, Ricci E, Marchetti C, Lang NP, Botticelli D. Early loading of single crowns supported by 6-mm-long implants with a moderately rough surface: a prospective 2-year follow-up cohort study. Clin Oral Implants Res. 2010 Sep;21(9):937-43.
28. Yoshinaga Y, Ukai T, Abe Y, Hara Y. Expression of receptor activator of nuclear factor kappa B ligand relates to inflammatory bone resorption, with or without occlusal trauma, in rats. J Periodontal Res. 2007 Oct;42(5):402-9.

29. Anitua E, Orive G. Short implants in maxillae and mandibles: a retrospective study with 1 to 8 years of follow-up. J Periodontol. 2010 Jun;81(6):819-26.

30. Lamster IB, Oshrain RL, Gordon JM. Enzyme activity in human gingival crevicular fluid: considerations in data reporting based on analysis of individual crevicular sites. J Clin Periodontol. 1986 Sep;13(8):799-804.

31. Zhuang LF, Watt RM, Mattheos N, Si MS, Lai, HC, Lang NP. Periodontal and peri-implant microbiota in patients with healthy and inflamed periodontal and peri-implant tissues. Clin Oral Implants Res. 2016 Jan;27(1):13-21.

32. Donovan R, Fetner A, Koutouzis T, Lundgren T. Crestal bone changes around implants with reduced abutment diameter placed non-submerged and at subcrestal positions: a 1-year radiographic evaluation. J Periodontol. 2010 Mar;81(3):428-34.

33. Neldam CA, Pinholt, EM. State of the art of short dental implants: a systematic review of the literature. Clin Implant Dent Relat Res. 2012 Aug;14(4):622-32.

34. Telleman G, Raghoebar GM, Vissink A, den Hartog L, Slater JJRH, Meijer HJA. A systematic review of the prognosis of short $(<10$ $\mathrm{mm}$ ) dental implants placed in the partially edentulous patient. J Clin Periodontol. 2011 Jul;38(7):667-76.

35. Moberg, LE, Kondell PA, Kullman L, Heimdahl A, Gynther GW. Evaluation of single tooth restorations on ITI dental implants: a prospective study on 29 patients. Clin Oral Implants Res. 1999 Feb;10(1):45-53.

36. Weber HP, Crohin CC, Fiorellini JP. A 5-year prospective clinical and radiographic study of non-submerged dental implants. Clin Oral Implants Res. 2000 Apr;11(2):144-53.

37. Camps-Font O, Burguen o-Barris G, Figueiredo R, Jung RE, GayEscoda C, Valmaseda-Castellon E. Interventions for Dental Implant Placement in Atrophic Edentulous Mandibles: Vertical Bone Augmentation and Alternative Treatments. A Meta- Analysis of Randomized Clinical Trials. J Periodontol. 2016 Dec;87(12):14441457

38. Tawil G, Aboujaoude N, Younan R. Influence of prosthetic parameters on the survival and complication rates of short implants. Int J Oral Maxillofac Implants 21:275-282.

39. Misch CE (2005) Short dental implants: a literature review and rationale for use. Dent Today. Mar-Apr 2006;21(2):275-82.

40. Gapski R,Wang HL, Mascarenhas P, Lang N. Critical review of immediate implant loading. Clin Oral Implants Res. 2003 Oct;14(5):515-27.

41. Guarnieri R, Di Nardo D, Gaimari G, Miccoli G, Testarelli L. Short vs. Standard Laser-Microgrooved Implants Supporting Single and Splinted Crowns: A Prospective Study with 3 Years Follow-Up. J Prosthodont. 2019 Feb;28(2):e771-e779. 